\title{
Pharmacokinetics and Tolerability of Single and Multiple Doses of Des- venlafaxine in Healthy Korean Subjects
}

\author{
Liang $\mathbf{Y}^{1 *}$, Qiu $\mathbf{R}^{2}$, Kim $\mathbf{S}^{3}$, Jang $\mathbf{I J}^{3}$, Lee $\mathbf{W S}^{4}$, Plotka $\mathrm{A}^{5}$ and Nichols $\mathrm{A}^{5}$ \\ ${ }^{1}$ Pfizer Inc., Groton, CT, USA \\ ${ }^{2}$ Pfizer Inc., Cambridge, MA, USA \\ ${ }^{3}$ Seoul National University College of Medicine and Hospital, Seoul, Republic of Korea \\ ${ }^{4}$ Pfizer Korea Inc., Seoul, Republic of Korea \\ ${ }^{5}$ Pfizer Inc., Collegeville, PA, USA
}

\begin{abstract}
Background: Racial and ethnic variations in CYP enzyme polymorphisms have been associated with population differences in drug metabolism. This study evaluated the pharmacokinetics of single- and multiple-dose desvenlafaxine in healthy Korean subjects.

Methods: This randomized, double-blind, placebo-controlled, study enrolled 38 healthy Korean adults (aged 18 to 55 years). Subjects received single oral doses of placebo or desvenlafaxine (administered as desvenlafaxine succinate) 50,100 , or $200 \mathrm{mg}$ on day 1 , followed by 5 days of once daily dosing on days 4 to 8 . Blood samples were collected pre-dose and over $72 \mathrm{~h}$ post-dose on days 1 and 8 . Plasma desvenlafaxine concentrations were measured using a validated high-performance liquid chromatography tandem mass spectrometry and pharmacokinetic parameters were calculated using non-compartmental method. Tolerability was assessed through adverse event reporting.

Results: For both single-and multiple-dose desvenlafaxine, peak plasma concentration and area under the concentration-time curve increased approximately linearly with dose. For the 4-fold increase in dose from $50 \mathrm{mg}$ to $200 \mathrm{mg}$ desvenlafaxine, area under the concentration-time curve from time 0 extrapolated to infinite time for singledose and area under the concentration-time curve from time 0-24 h for multiple-dose administration increased 4.3and 4.1 -fold, respectively; peak plasma concentration values increased 4.5- and 4.3-fold, respectively. Mean apparent half-life ranged from 10.75-13.49 $\mathrm{h}$ across all doses following single and multiple dose administration. Accumulation ratios for area under the concentration-time curve ranged from 1.478 to 1.669 (peak plasma concentration, 1.4881.578). No serious or severe adverse events were reported.

Conclusion: The pharmacokinetics of multiple-dose desvenlafaxine 50-200 mg was linear and was able to be predicted from single-dose pharmacokinetics in Korean subjects. Pharmacokinetic parameters were similar to values previously observed in other racial/ethnic populations. There were no new safety findings for desvenlafaxine.
\end{abstract}

Keywords: Desvenlafaxine; Antidepressiveagents; Pharmacokinetics; Cytochrome P-450 CYP2D6

\section{Introduction}

Desvenlafaxine is a Serotonin-Norepinephrine Reuptake Inhibitor (SNRI) with demonstrated efficacy for improving symptoms of Major Depressive Disorder (MDD) in adults over the dose range of $50 \mathrm{mg} / \mathrm{d}$ to $400 \mathrm{mg} / \mathrm{d}$ [1-10]. Desvenlafaxine (administered as desvenlafaxine succinate) is approved at the $50 \mathrm{mg} / \mathrm{d}$ and $100 \mathrm{mg} / \mathrm{d}$ doses in more than 30 countries; the recommended therapeutic dose is $50 \mathrm{mg} / \mathrm{d}$ [11]. The pharmacokinetic profile of single-dose and multiple-dose desvenlafaxine, examined in multiple studies [12-16], was found to be linear and doseproportional over the dose range of $50 \mathrm{mg} / \mathrm{d}$ to $600 \mathrm{mg} / \mathrm{d}[15,16]$.

Pharmacokinetic studies of desvenlafaxine have been largely based on Caucasian or African American populations [12-17]. However, population differences in drug metabolism linked to variations in the incidence of hepatic Cytochrome P450 (CYP) enzyme polymorphisms have been observed for some drugs [18-21]. For example, CYP2D6 based drug metabolism can vary substantially between East Asian (including Chinese, Japanese and Korean) and Caucasian populations $[18,20,22,23]$. However, desvenlafaxine is primarily eliminated via phase II glucuronidation and renal excretion, with minimal phase I CYP3A4 hepatic metabolism [11,24]. Race differences in desvenlafaxine pharmacokinetics therefore are not predicted by its metabolic profile. Analysis of desvenlafaxine pharmacokinetics has been carried out in non-US and European populations and no notable differences were observed between racial groups in those studies $[25,26]$. Desvenlafaxine has been in development for the MDD indication in Korea, and the current study was therefore designed to assess desvenlafaxine pharmacokinetics in a Korean population. The objective of this study was to evaluate single- and multiple-dose desvenlafaxine pharmacokinetics, safety, and tolerability in healthy Korean adults.

\section{Methods}

\section{Study design}

This was a randomized, double-blind, placebo-controlled, parallelgroup study of desvenlafaxine pharmacokinetics following single oral

*Corresponding author: Liang Y, MS, Senior Associate, Pfizer, 445 Eastern Point Road-MS8260-2241, Groton, CT 06340, USA, Tel: 860441 6952; E-mail: yali.liang@pfizer.com

Received November 11, 2016; Accepted January 10, 2017; Published January 27,2017

Citation: Liang Y, Qiu R, Kim S, Jang IJ, Lee WS, et al. (2017) Pharmacokinetics and Tolerability of Single and Multiple Doses of Desvenlafaxine in Healthy Korean Subjects. J Bioequiv Availab 9: 341-345. doi: 10.4172/jbb.1000322

Copyright: ( 2017 Liang Y, et al. This is an open-access article distributed under the terms of the Creative Commons Attribution License, which permits unrestricted use, distribution, and reproduction in any medium, provided the original author and source are credited. 
doses and after 5 days of once daily dosing in healthy Korean subjects. Desvenlafaxine dose levels of $50 \mathrm{mg}, 100 \mathrm{mg}$, and $200 \mathrm{mg}$ were evaluated. Subjects were randomly assigned in a 5:1 ratio (desvenlafaxine: placebo) at each of the 3 doses. The study was conducted at one study site in the Republic of Korea between November and December 2011, and was in compliance with the ethical principles of the Declaration of Helsinki and the International Conference on Harmonization Good Clinical Practice Guidelines. The site's institutional review board provided protocol approval and study oversight. Written informed consent was obtained from all subjects before screening.

\section{Subjects}

The study enrolled male and non-pregnant/non-lactating female adults (aged 18-55 years) with a body mass index of $17.5-30.5 \mathrm{~kg} / \mathrm{m}^{2}$ and total body weight greater than $50 \mathrm{~kg}$. All subjects were Asian with a racial designation of Korean. Enrolled subjects were healthy, based on medical history, physical examination, vital signs, clinical laboratory test results, and 12-lead Electrocardiogram (ECG), and smoked no more than 5 cigarettes per day (or the equivalent tobacco- or nicotinecontaining products). Subjects were excluded from the study if they had evidence or history of clinically significant hematologic, renal, endocrine, pulmonary, gastrointestinal, cardiovascular, hepatic, psychiatric, neurologic, or allergic disease; any condition possibly affecting drug absorption (e.g. gastrectomy); drug abuse; or regular alcohol consumption exceeding 14 drinks/week for females or 21 drinks/week for males within 6 months of screening. Use of any of the following drugs was prohibited: investigational drugs within 30 days or 5 half-lives (whichever was longer) before day 1; prescription or nonprescription drugs (except acetaminophen/paracetamol) and dietary supplements within 7 days (or 5 half-lives) before day 1; and herbal supplements and hormonal methods of contraception or hormone therapy within 28 days.

\section{Study procedures}

Each subject received a single oral dose of desvenlafaxine or placebo on study day 1 , and then daily dosing on days 4 through 8 . On day 1 , subjects were dosed after an overnight fast of at least $8 \mathrm{~h}$. On day 4 through 7 , subjects received a breakfast approximately 30 minutes before study drug administration. On the morning of day 8 , subjects received the last dose of study drug after an overnight fast of at least $8 \mathrm{~h}$. Serial blood samples $(4 \mathrm{~mL})$ for pharmacokinetic analysis were collected in tubes containing potassium ethylenediamine tetraacetic acid before (pre-dose), and (0.5, 1, 2, 4, 6, 8, 10, 12, 16, 24, 36, 48, 72) h after study drug administration on days 1 and 8 . Samples were centrifuged at approximately $1700 \times \mathrm{g}$ for $10 \mathrm{~min}$ at $4^{\circ} \mathrm{C}$ and plasma was stored at approximately $-20^{\circ} \mathrm{C}$ within $1 \mathrm{~h}$ of collection, and stored at $-20^{\circ} \mathrm{C} \pm 5^{\circ} \mathrm{C}$ until analysis, within 77 days.

\section{Bioanalytical methods}

Plasma desvenlafaxine was quantitated using a protein precipitation extraction. Plasma samples were analyzed for desvenlafaxine concentrations at WuXi AppTec (Shanghai, People's Republic of China) using validated high-performance liquid chromatographic tandem mass spectrometry using nadolol as an internal standard and venlafaxine and O-desmethylvenlafaxine (the free base of desvenlafaxine) as reference standards. The peak area ratios of internal and reference standards were determined using Analyst Version 1.5.1 or Version 1.4.2 (Applied Biosystems, Foster City, CA, USA) and desvenlafaxine concentrations were calculated by Watson "LIMS Version 7.2.0.02 (Thermo Fisher Scientific, Philadelphia, PA, United
States). Calibration standard responses were linear over the range of $2.00 \mathrm{ng} / \mathrm{mL}$ to $500 \mathrm{ng} / \mathrm{mL}$. The lower limit of quantification (LLOQ) for desmethylvenlafaxine was $2.00 \mathrm{ng} / \mathrm{mL}$. Samples with concentrations below the LLOQ were set to $0 \mathrm{ng} / \mathrm{mL}$.

Between-day assay accuracy (percent relative error) for quality control (QC) concentrations, ranged from $-1.1 \%$ to $1.8 \%$ for the low (5.00 ng/mL), medium (45.0 ng/mL), high $(375 \mathrm{ng} / \mathrm{mL})$, and diluted $(2500 \mathrm{ng} / \mathrm{mL})$ QC samples. Assay precision, expressed as the betweenday percent coefficients of variation $(\% \mathrm{CV})$ of the mean estimated concentrations of QC samples was $\leq 3.9 \%$ for the low, medium, high, and diluted concentrations.

\section{Pharmacokinetic analyses}

Desvenlafaxine plasma concentrations were analyzed using noncompartmental analysis of concentration versus time data. Peak concentration $\left(\mathrm{C}_{\max }\right)$ and time to $\mathrm{C}_{\max }\left(\mathrm{T}_{\max }\right)$ were observed directly from the data. Total area under the drug concentration-time curve from time 0 to the time of the last quantifiable concentration $\left(\mathrm{AUC}_{\text {last }}\right)$ and from time $0-24 \mathrm{~h}\left(\mathrm{AUC}_{24}\right)$ were estimated using the linear/log trapezoidal method. AUC from time 0 extrapolated to infinite time $\left(\mathrm{AUC}_{\infty}\right)$ was calculated based on $\mathrm{AUC}_{\text {last }}+\left(\mathrm{C}_{\text {last }}{ }^{*} / \mathrm{kel}\right)$, where $\mathrm{C}_{\text {last }}{ }^{*}$ is the predicted plasma concentration at the last quantifiable time point estimated from the log-linear regression analysis and $\mathrm{k}_{\mathrm{el}}$ is the terminal phase elimination rate constant. The terminal-phase elimination half-life $\left(t_{1 / 2}\right)$ was calculated as $t_{1 / 2}=\ln (2) / k_{\mathrm{el}}$. Apparent oral dose clearance $(\mathrm{Cl} / \mathrm{F})$ was estimated as the day 1 dose/AUC and day 8 dose/ $\mathrm{AUC}_{24}$. Apparent volume of distribution for the terminal disposition phase $\left(\mathrm{V}_{\mathrm{z}} / \mathrm{F}\right)$ was calculated as the ratio of $\mathrm{Cl} / \mathrm{F}$ to $\mathrm{k}_{\mathrm{el}}$. The observed accumulation ratio for AUC $\left(\mathrm{R}_{\mathrm{ac}}\right)$ was defined as the ratio of day 8 $\mathrm{AUC}_{24}$ to day $1 \mathrm{AUC}_{24}$ and the accumulation ratio for $\mathrm{C}_{\max }\left(\mathrm{R}_{\mathrm{ac}}, \mathrm{C}_{\max }\right.$ was the ratio of day $8 \mathrm{C}_{\max }$ to day $1 \mathrm{C}_{\max }$. The parameters of $A \mathrm{UC}_{\infty}$, $\mathrm{t}_{1 / 2}, \mathrm{Cl} / \mathrm{F}$, and $\mathrm{V}_{\mathrm{z}} / \mathrm{F}$ were reported only if a well-characterized terminal phase, defined as at least 3 data points with a goodness-of-fit statistic for the log-linear regression $\left(r^{2}\right) \geq 0.9$ and a span ratio (duration over which $t_{1 / 2}$ was assessed, divided by the $t_{1 / 2}$ estimate) $\geq 2$, was observed. The attainment of steady-state was assessed using a median plot of the pre-dose concentrations on days 7,8 , and 9 .

\section{Safety assessments}

Safety and tolerability assessments included Adverse Event (AE) reports, clinical laboratory evaluations (blood chemistry, hematology, and urinalyses), physical examination, vital sign measurements, and 12-lead ECGs. Safety assessments were made at baseline, at scheduled intervals post-dose, and at final study evaluation ( $72 \mathrm{~h}$ after final dose). Adverse events were monitored throughout the study period and reported using terminology from the Medical Dictionary for Regulatory Activities (version 14.1). Treatment-emergent AEs (TEAEs), defined as AEs that occurred or increased in severity following the start of treatment, were tabulated by dose. Vital signs, ECGs, and laboratory test results were evaluated for potential clinical importance using predetermined criteria. All subjects who received at least 1 dose of study medication were included in safety analyses.

\section{Statistical analysis}

Plasma desvenlafaxine concentrations were summarized by dose and sampling time; pharmacokinetic parameters were summarized descriptively by dose. Summary statistics for $\mathrm{AUC}_{0-24}, \mathrm{AUC}_{\infty}, \mathrm{C}_{\max }$ $\mathrm{t}_{1 / 2}, \mathrm{CL} / \mathrm{F}, \mathrm{V}_{\mathrm{z}} / \mathrm{F}$, and $\mathrm{R}_{\mathrm{ac}}$ included arithmetic mean, median, Coefficient of Variation (CV\%), standard deviation, minimum, maximum, and geometric mean (except for $\mathrm{t}_{1 / 2}$ ); $\mathrm{T}_{\max }$ was summarized using median, 
minimum, and maximum. Relationships between pharmacokinetic parameters and dose were assessed visually using plots of dosenormalized parameters vs. dose for individual subject values and geometric means. No formal inferential statistics were applied to pharmacokinetic or safety data.

\section{Results}

\section{Study population}

A total of 38 subjects were randomly assigned; 37 subjects (24 male, 13 female) received at least 1 dose of study drug and comprised the safety population. Demographic and baseline characteristics were similar between treatment groups (Table 1). One subject chose to discontinue the study after receiving desvenlafaxine $100 \mathrm{mg}$ on day 1 and was excluded from pharmacokinetic analyses. Pharmacokinetic data were analyzed for 30 subjects who received desvenlafaxine and completed the study; subjects assigned to placebo $(n=6)$ were not included in the pharmacokinetic analysis.

Data from 2 subjects were removed from the pharmacokinetic summary: on day 1,1 subject taking desvenlafaxine $200 \mathrm{mg}$ was excluded because of vomiting within $2 \mathrm{~h}$ after dosing, and on day 8,1 subject taking desvenlafaxine $100 \mathrm{mg}$ was excluded for low or undetectable plasma desvenlafaxine concentrations. The reason for anomalous concentrations could not be determined.

\section{Pharmacokinetics}

Figure 1 shows median plasma concentrations of desvenlafaxine over time after administration of single and multiple doses of desvenlafaxine $50 \mathrm{mg}, 100 \mathrm{mg}$, and $200 \mathrm{mg}$. Median $\mathrm{T}_{\max }$ ranged from 4.00 (desvenlafaxine $50 \mathrm{mg}$ ) to $6.00 \mathrm{~h}$ (desvenlafaxine $200 \mathrm{mg}$ ) after single dose desvenlafaxine and was $4.00 \mathrm{~h}$ post-dose for each desvenlafaxine dose after 5 days of daily dosing. Steady-state exposures appeared to be reached after 4 days of daily dosing (day 7), based on similar median trough (pre-dose) concentrations on days 7 to 9 .

Pharmacokinetic parameters for plasma desvenlafaxine are summarized by dose group for single- and multiple-dose administration in Table 2. The mean $t_{1 / 2}$ was consistent across doses with single- and multiple-dose administration. Single- and multiple-dose $\mathrm{AUC}_{24}$ and $\mathrm{C}_{\text {max }}$ increased approximately proportionally with increasing desvenlafaxine dose. For single-dose desvenlafaxine, geometric mean $\mathrm{C}_{\max }$ increased 2.5 -fold between the 50- and 100-mg dose groups and 1.8-fold between 100- and 200-mg doses; respective increases in $\mathrm{AUC}_{\infty}$ were 2.3- and

\begin{tabular}{|c|c|c|c|c|}
\hline & \multicolumn{3}{|c|}{ Desvenlafaxine Dose Group } & \multirow{2}{*}{$\begin{array}{c}\text { Placebo } \\
(n=6)\end{array}$} \\
\hline & $\begin{array}{l}50 \mathrm{mg} \\
(\mathrm{n}=10)\end{array}$ & $\begin{array}{c}100 \mathrm{mg} \\
(\mathrm{n}=11)\end{array}$ & $\begin{array}{c}200 \mathrm{mg} \\
(\mathrm{n}=10)\end{array}$ & \\
\hline \multicolumn{5}{|c|}{ Age (year) } \\
\hline Mean (SD) & $26.7(4.6)$ & $26.2(4.0)$ & $26.7(7.5)$ & $24.2(3.9)$ \\
\hline Range & $21-36$ & 21-32 & $21-46$ & 20-31 \\
\hline \multicolumn{5}{|c|}{ Sex, $n(\%)$} \\
\hline Female & $2(20)$ & $6(55)$ & $2(20)$ & $3(50)$ \\
\hline Male & $8(80)$ & $5(45)$ & $8(80)$ & $3(50)$ \\
\hline \multicolumn{5}{|c|}{ Height (cm) } \\
\hline Mean (SD) & $170.1(5.6)$ & $167.1(8.7)$ & $172.9(7.8)$ & $167.3(6.3)$ \\
\hline \multicolumn{5}{|c|}{ Weight (kg) } \\
\hline Mean (SD) & $62.4(8.5)$ & $63.6(7.5)$ & $63.9(6.8)$ & $64.8(9.4)$ \\
\hline \multicolumn{5}{|c|}{ BMI $\left(\mathbf{k g} / \mathbf{m}^{2}\right)$} \\
\hline Mean (SD) & $21.5(2.0)$ & $22.7(1.4)$ & $21.4(1.9)$ & $23.1(2.7)$ \\
\hline
\end{tabular}

BMI: Body Mass Index; SD: Standard Deviation.

Table 1: Baseline demographic and clinical characteristics, safety population. 1.9-fold. For multiple-dose desvenlafaxine, geometric mean $\mathrm{C}_{\max }$ increased 2.4 -fold from the $50 \mathrm{mg}$ to the $100 \mathrm{mg}$ dose, and 1.8 -fold from $100 \mathrm{mg}$ to $200 \mathrm{mg}$; $\mathrm{AUC}_{24}$ increased 2.5- and 1.6-fold, respectively. For the 4-fold increase in dose from $50 \mathrm{mg}$ to $200 \mathrm{mg}$ desvenlafaxine, $\mathrm{AUC}_{\infty}$ for single-dose and $\mathrm{AUC}_{24}$ for multiple-dose administration increased 4.3- and 4.1-fold, respectively; $\mathrm{C}_{\max }$ values increased 4.5and 4.3 -fold for single-dose and multiple-dose, respectively. Figure 2 shows dose normalized $\mathrm{C}_{\max }$ and $\mathrm{AUC}_{24}$ in comparison to data from a US population for multiple-dose desvenlafaxine $50 \mathrm{mg}$ [16]. Mean weight-normalized $\mathrm{Cl} / \mathrm{F}$ was similar across the dose groups following single- and multiple-dose desvenlafaxine (Table 2). Accumulation of desvenlafaxine exposure $\left(\mathrm{AUC}_{24}\right)$ at steady state was approximately 1.5-1.7-fold compared with single-dose conditions and appeared to be independent of dose.

\section{Safety}

TEAEs were reported by $16(52 \%)$ subjects in the desvenlafaxine groups (50 mg, 3/10; $100 \mathrm{mg}, 7 / 11 ; 200 \mathrm{mg}, 6 / 10)$ and 2 (33\%) subjects in the placebo group. Nausea and headache were the only TEAEs reported by 2 or more subjects in any treatment group. Nausea was reported by $3 / 10,6 / 11$, and $4 / 10$ subjects in the desvenlafaxine $50 \mathrm{mg}$, $100 \mathrm{mg}$, and $200 \mathrm{mg}$ groups, respectively (placebo, 0 ), and headache was reported by $2 / 10,0 / 11$, and $1 / 10$ subjects, respectively (placebo, $1 / 6)$. No subjects discontinued due to AEs or experienced serious or severe AEs during the study

Laboratory test results of potential clinical importance were observed in 16/31 subjects receiving desvenlafaxine and 3/6 subjects receiving placebo. None of those results were considered clinically significant. Vital sign measures of potential clinical importance were reported in 4 subjects receiving desvenlafaxine and 4 subjects receiving placebo, and ECG results of potential clinical importance were reported in 12 subjects receiving desvenlafaxine and 1 subject receiving placebo. None were considered clinically significant.

\section{Discussion}

This study is the first to provide pharmacokinetic and safety data for oral desvenlafaxine in healthy Korean adults. Under both singleand multiple-dose conditions, there was an approximately linear relationship between desvenlafaxine dose and exposure (AUC and $\mathrm{C}_{\max }$ ) over the dose range of $50 \mathrm{mg}$ to $200 \mathrm{mg}$. Dose normalized AUC, $\mathrm{C}_{\max }$ and $\mathrm{CL} / \mathrm{F}$ values were similar across dose groups and showed no visible trend to increase or decrease with increasing desvenlafaxine dose. Multiple-dose pharmacokinetics was able to be adequately predicted from single-dose pharmacokinetics, with no unexpected accumulation of desvenlafaxine following daily doses of $50 \mathrm{mg}, 100 \mathrm{mg}$, and $200 \mathrm{mg}$ for 5 days.

Pharmacokinetic profiles for single- and multiple-dose desvenlafaxine in healthy Korean subjects were similar to those previously observed in healthy mixed (African American and Caucasian) US populations [15,16], and in Chinese [26] and Japanese [25] subjects. These results are not expected, given the simple metabolic pathway of desvenlafaxine, which is largely independent of the CYP isoenzyme pathways $[11,24]$. For the healthy adult Korean subjects receiving multiple-dose desvenlafaxine $50 \mathrm{mg}$ in the current study, the geometric mean $\mathrm{AUC}_{24}$ was $2845 \mathrm{ng} \cdot \mathrm{h} / \mathrm{mL}$ and $\mathrm{C}_{\max }$ was $168 \mathrm{ng} / \mathrm{mL}$, and median $\mathrm{T}_{\max }$ was $4.0 \mathrm{~h}$ after 5 days of daily dosing. Similar values were reported in a study in 28 US subjects (64\% African American, $21 \%$ Caucasian) receiving desvenlafaxine $50 \mathrm{mg}$ for 5 days $\left(\mathrm{AUC}_{24}=\right.$ $2853 \mathrm{ng} \cdot \mathrm{h} / \mathrm{mL}$, and $\mathrm{C}_{\text {max }}=174 \mathrm{ng} / \mathrm{mL}$; median $\mathrm{T}_{\max }=4.0 \mathrm{~h}$ ) [16]. Other 
Citation: Liang Y, Qiu R, Kim S, Jang IJ, Lee WS, et al. (2017) Pharmacokinetics and Tolerability of Single and Multiple Doses of Desvenlafaxine in Healthy Korean Subjects. J Bioequiv Availab 9: 341-345. doi: 10.4172/jbb.1000322

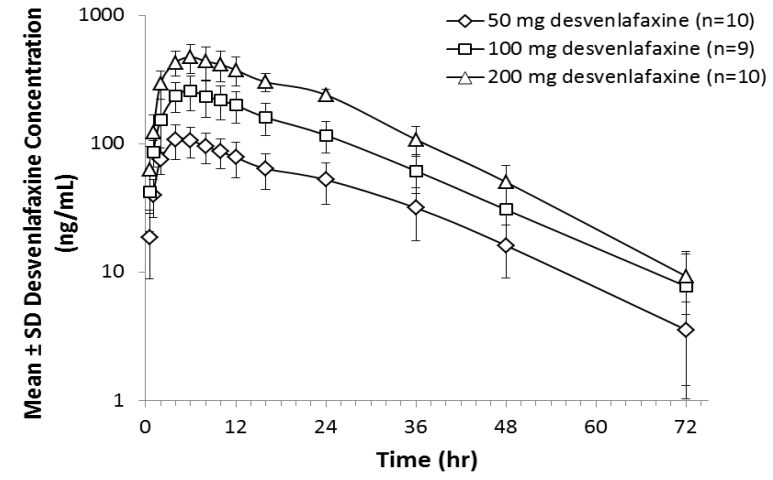

A

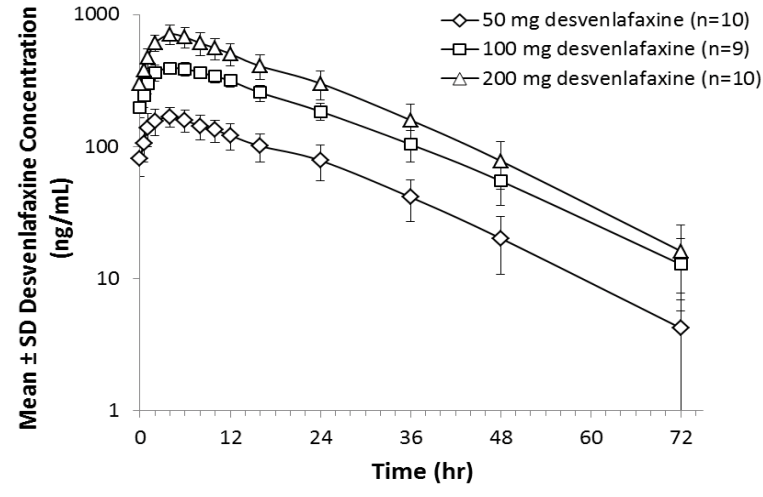

B

Figure 1: Mean $\pm S D$ desvenlafaxine plasma concentration vs. time in healthy Korean subjects following (A) single-dose desvenlafaxine and (B) multiple-dose desvenlafaxine (after 5 days of daily dosing). Data from one subject in the desvenlafaxine $200 \mathrm{mg}$ group on day 1 (single-dose) was excluded due to vomiting which occurred within $2 \mathrm{~h}$ postdosing. Data from one subject in the desvenlafaxine $100 \mathrm{mg}$ groups was excluded from the multiple dose analysis due to low or undetectable concentrations on days 7 and 8.

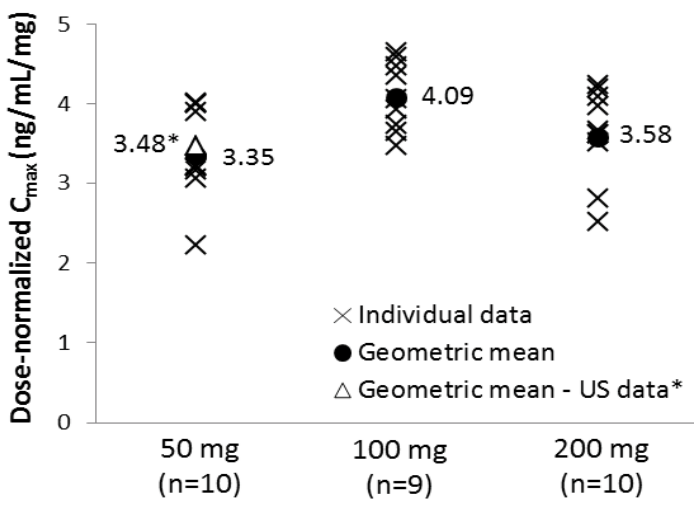

Desvenlafaxine Dose

\section{A}

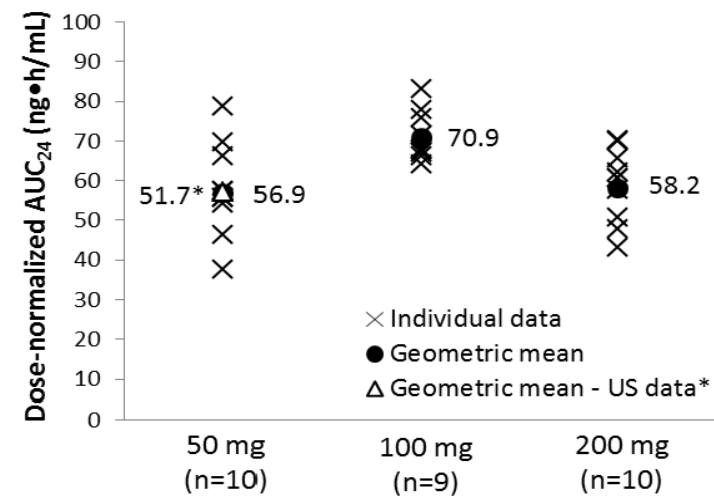

Desvenlafaxine Dose

Figure 2: Dose-normalized (A) $C$ and (B) $A \cup C_{24}$ for plasma concentrations of desvenlafaxine after 5 days of daily dosing. Data from one subject in the desvenlafaxine $100 \mathrm{mg}$ group was excluded due to low or undetectable plasma concentrations on days 7 and 8 . *US data from Nichols et al. [16]. $\mathrm{C}_{\max }$ : Peak plasma concentration; $\mathrm{AUC}_{24}$ : Area under the plasma concentration-time curve from time $0-24 \mathrm{~h}$ post-dose.

\begin{tabular}{|c|c|c|c|c|c|c|}
\hline \multirow[b]{2}{*}{ Parameter $^{\mathrm{a}}$} & \multicolumn{3}{|c|}{ Single Desvenlafaxine Dose (Day 1) } & \multicolumn{3}{|c|}{ Multiple Desvenlafaxine Doses (Day 8) } \\
\hline & $\begin{array}{l}50 \mathrm{mg} \\
(\mathrm{n}=10)\end{array}$ & $\begin{array}{l}100 \mathrm{mg} \\
(\mathrm{n}=10)\end{array}$ & $\begin{array}{c}200 \mathrm{mg} \\
(\mathrm{n}=9)\end{array}$ & $\begin{array}{l}50 \mathrm{mg} \\
(\mathrm{n}=10)\end{array}$ & $\begin{array}{c}100 \mathrm{mg} \\
(\mathrm{n}=9)\end{array}$ & $\begin{array}{c}200 \mathrm{mg} \\
(\mathrm{n}=10)\end{array}$ \\
\hline $\mathrm{AUC}_{\infty}, \mathrm{ng} \cdot \mathrm{h} / \mathrm{mL}$ & $2709(29)$ & $6244(20)$ & $11580(8)$ & ND & ND & ND \\
\hline $\mathrm{AUC}_{24}, \mathrm{ng} \cdot \mathrm{h} / \mathrm{mL}$ & $1706(28)$ & $4119(24)$ & $7886(15)$ & $2845(20)$ & $7094(9)$ & $11620(16)$ \\
\hline $\mathrm{C}_{\max }, \mathrm{ng} / \mathrm{mL}$ & $106.1(28)$ & $261.4(28)$ & $476.2(25)$ & $167.5(17)$ & $408.5(11)$ & $715.3(16)$ \\
\hline $\mathrm{T}_{\max }, \mathrm{h}$ & $4.0(4.0-8.0)$ & $5.0(4.0-10.0)$ & $6.0(2.0-10.0)$ & $4.0(1.0-4.0)$ & $4.0(2.0-8.0)$ & $4.0(2.0-6.0)$ \\
\hline$t_{1 / 2}, h$ & $13.49(21)$ & $12.81(33)$ & $10.75(16)$ & $12.56(19)$ & $12.92(19)$ & $11.97(18)$ \\
\hline $\mathrm{Cl} / \mathrm{F} / \mathrm{Wt}, \mathrm{L} / \mathrm{h} / \mathrm{kg}$ & $0.298(27)$ & $0.253(37)$ & $0.271(9)$ & $0.284(18)$ & $0.227(11)$ & $0.271(11)$ \\
\hline $\mathrm{V}_{\mathrm{z}} / \mathrm{F}, \mathrm{L}$ & $352.5(30)$ & $282.0(36)$ & $265.0(17)$ & $314.0(24)$ & $259.2(25)$ & $292.5(24)$ \\
\hline $\mathrm{R}_{\mathrm{ac}}$ & ND & ND & ND & $1.663(21)$ & $1.669(26)$ & $1.478(13)$ \\
\hline $\mathrm{R}_{\mathrm{ac}}, \mathrm{C}_{\max }$ & ND & ND & ND & $1.578(17)$ & $1.488(22)$ & $1.499(30)$ \\
\hline
\end{tabular}

AUC $_{\infty}$ : Area under the plasma concentration-versus-time curve from time 0 extrapolated to infinite time; $\mathrm{AUC}_{24}$ : Total area under the plasma concentration-versus-time curve from time 0-24 h; $\mathrm{C}_{\text {max }}$ : Peak plasma concentration; Cl/F: Apparent clearance; ND: Value not determined; $R_{a}$ : Accumulation ratio for AUC; $\mathrm{C}_{\mathrm{max}}$ : Accumulation ratio for $\mathrm{C}_{\max } ; \mathrm{T}_{\max }$ : Time of peak concentration; $\mathrm{t}_{1 / 2}$ : Terminal elimination half-life; $\mathrm{Vz} / \mathrm{F}$ : Apparent volume of distribution; Wt: Weight.

${ }^{a}$ Geometric mean (\%CV) for all except: median (range) for $\mathrm{T}_{\text {max }}$; Arithmetic mean (\%CV) for $\mathrm{t}_{1 / 2}$.

Table 2: Plasma desvenlafaxine pharmacokinetic parameters in healthy Korean subjects following single and multiple doses of desvenlafaxine. 
Citation: Liang Y, Qiu R, Kim S, Jang IJ, Lee WS, et al. (2017) Pharmacokinetics and Tolerability of Single and Multiple Doses of Desvenlafaxine in Healthy Korean Subjects. J Bioequiv Availab 9: 341-345. doi: 10.4172/jbb.1000322

studies of single- and multiple-dose administration in US and French subjects have demonstrated that desvenlafaxine $\mathrm{C}_{\max }$ and AUC increase in a linear, dose-proportional manner over the dose range of 150-900 $\mathrm{mg} /$ day [15].

There were no new safety findings in this study. No severe or serious AEs were reported, and no clinically important changes in clinical laboratory values, vital signs, or ECG recordings were observed. The most common TEAEs, nausea and headache, were reported in other pharmacokinetic studies of desvenlafaxine in healthy adults [15$17,25,27]$ and in a pooled analysis of 9 studies of desvenlafaxine (50$400 \mathrm{mg}$ for 8 weeks) in patients with MDD [28].

\section{Conclusion}

In healthy Korean subjects administered desvenlafaxine $50 \mathrm{mg}$ to $200 \mathrm{mg}$, multiple-dose pharmacokinetics was dose proportional and was predicted from single-dose pharmacokinetics. Pharmacokinetic parameters in this population were similar to values observed in nonAsian populations. There were no new safety findings for desvenlafaxine in this study.

\section{Acknowledgment}

This study was sponsored by Pfizer. Medical writing support was provided by Kathleen Dorries, $\mathrm{PhD}$, and Lela Creutz, $\mathrm{PhD}$, of Peloton Advantage and was funded by Pfizer.

\section{Disclosures}

$\mathrm{YL}$ and $\mathrm{AP}$ are employees of Pfizer Inc. RQ, WSL and $\mathrm{AN}$ are former employees of Pfizer Inc. SK and IJJ have nothing to disclose.

\section{References}

1. DeMartinis NA, Yeung PP, Entsuah R, Manley AL (2007) A double-blind placebo-controlled study of the efficacy and safety of desvenlafaxine succinate in the treatment of major depressive disorder. J Clin Psychiatry 68: 677-688.

2. Septien-Velez L, Pitrosky B, Padmanabhan SK, Germain JM, Tourian KA (2007) A randomized, double-blind, placebo-controlled trial of desvenlafaxine succinate in the treatment of major depressive disorder. Int Clin Psychopharmacol 22: 338-347

3. Liebowitz MR, Manley AL, Padmanabhan SK, Ganguly R, Tummala R, et al (2008) Efficacy, safety, and tolerability of desvenlafaxine $50 \mathrm{mg} /$ day and 100 mg/day in outpatients with major depressive disorder. Curr Med Res Opin 24 1877-1890.

4. Boyer P, Montgomery S, Lepola U, Germain JM, Brisard C, et al. (2008) Efficacy, safety, and tolerability of fixed-dose desvenlafaxine 50 and 100 $\mathrm{mg} /$ day for major depressive disorder in a placebo-controlled trial. Int Clin Psychopharmacol 23: 243-253.

5. Kornstein SG, Jiang Q, Reddy S, Musgnung JJ, Guico-Pabia CJ (2010) Shortterm efficacy and safety of desvenlafaxine in a randomized, placebo-controlled study of perimenopausal and postmenopausal women with major depressive disorder. J Clin Psychiatry 71: 1088-1096.

6. Tourian KA, Padmanabhan SK, Groark J, Brisard C, Farrington D (2009) Desvenlafaxine 50 and $100 \mathrm{mg} / \mathrm{d}$ in the treatment of major depressive disorder: an 8-week, phase III, multicenter, randomized, double-blind, placebocontrolled, parallel-group trial and a post hoc pooled analysis of three studies. Clin Ther $31 \mathrm{Pt}$ 1: 1405-1423.

7. Dunlop BW, Reddy S, Yang L, Lubaczewski S, FochtK, et al. (2011) Symptomatic and functional improvement in employed depressed patients: a double-blind clinical trial of desvenlafaxine versus placebo. J Clin Psychopharmacol 31: 569-576.

8. Iwata N, Tourian KA, Hwang E, Mele L, Vialet C (2013) Efficacy and safety of desvenlafaxine 25 and $50 \mathrm{mg} /$ day in a randomized, placebo-controlled study of depressed outpatients. J Psychiatr Pract 19: 5-14.

9. Clayton AH, Kornstein SG, Dunlop BW, Focht K, Musgnung J, et al. (2013) Efficacy and safety of desvenlafaxine $50 \mathrm{mg} / \mathrm{d}$ in a randomized, placebocontrolled study of perimenopausal and postmenopausal women with major depressive disorder. J Clin Psychiatry 74: 1010-1017.
10. Clayton AH, Tourian KA, Focht K, Hwang E, Cheng RF, et al. (2015) Desvenlafaxine 50 and $100 \mathrm{mg} / \mathrm{d}$ versus placebo for the treatment of major depressive disorder: a phase 4, randomized controlled trial. J Clin Psychiatry 76: 562-569.

11. Centers for Disease Control and Prevention (CDC) (2013) Use of 13-valent pneumococcal conjugate vaccine and 23 -valent pneumococcal polysaccharide vaccine among children aged $6-18$ years with immunocompromising conditions: recommendations of the Advisory Committee on Immunization Practices (ACIP). MMWR Morb Mortal Wkly Rep 62: 521-524.

12. Nichols AI, Richards LS, Behrle JA, Posener JA, McGrory SB, et al. (2011) The pharmacokinetics and safety of desvenlafaxine in subjects with chronic renal impairment. Int J Clin Pharmacol Ther 49: 3-13.

13. Nichols Al, Focht K, Jiang Q, Preskorn SH, Kane CP (2011) Pharmacokinetics of venlafaxine extended release $75 \mathrm{mg}$ and desvenlafaxine $50 \mathrm{mg}$ in healthy CYP2D6 extensive and poor metabolizers: a randomized, open-label, twoperiod, parallel-group, crossover study. Clin Drug Investig 31: 155-167.

14. Baird-Bellaire S, Behrle JA, Parker VD, Patat A, Paul J, et al. (2013) An open-label, single-dose, parallel-group study of the effects of chronic hepatic impairment on the safety and pharmacokinetics of desvenlafaxine. Clin Ther 35: 782-794.

15. Nichols AI, Behrle JA, Parks V, Richards LS, McGrory SB, et al. (2013) Pharmacokinetics, pharmacodynamics, and safety of desvenlafaxine, a serotonin-norepinephrine reuptake inhibitor. J Bioequiv Availab 5: 22-30.

16. Nichols A, Liang Y, Matschke K, Paul J, Behrle J, et al. (2013) An evaluation of the potential of cytochrome P450 3A4-mediated drug-drug interactions with desvenlafaxine use. J Bioequiv Availab 5: 53-59.

17. Nichols Al, Fatato P, Shenouda M, Paul J, Isler JA, et al. (2009) The effects of desvenlafaxine and paroxetine on the pharmacokinetics of the cytochrome P450 2D6 substrate desipramine in healthy adults. J Clin Pharmacol 49: 219-228.

18. Bjornsson TD, Wagner JA, Donahue SR, Harper D, Karim A, et al. (2003) $A$ review and assessment of potential sources of ethnic differences in drug responsiveness. J Clin Pharmacol 43: 943-967.

19. Bertilsson L (2007) Metabolism of antidepressant and neuroleptic drugs by cytochrome p450s: clinical and interethnic aspects. Clin Pharmacol Ther 82 606-609.

20. Johansson I, Oscarson M, Yue QY, Bertilsson L, Sjoqvist F, et al. (1994) Genetic analysis of the Chinese cytochrome P4502D locus: characterization of variant CYP2D6 genes present in subjects with diminished capacity for debrisoquine hydroxylation. Mol Pharmacol 46: 452-459.

21. Lobello KW, Preskorn SH, Guico-Pabia CJ, Jiang Q, Paul J, et al. (2010) Cytochrome P450 2D6 phenotype predicts antidepressant efficacy of venlafaxine: a secondary analysis of 4 studies in major depressive disorder. $J$ Clin Psychiatry 71: 1482-1487.

22. Bradford LD (2002) CYP2D6 allele frequency in European Caucasians, Asians Africans and their descendants. Pharmacogenomics 3: 229-243.

23. Johansson I, Yue QY, Dahl ML, Heim M, Sawe J, et al. (1991) Genetic analysis of the interethnic difference between Chinese and Caucasians in the polymorphic metabolism of debrisoquine and codeine. Eur J Clin Pharmacol 40: 553-556.

24. DeMaio W, Kane CP, Nichols Al, Jordan R (2011) Metabolism studies of desvenlafaxine. J Bioequiv Availab 3: 151-160

25. Ono C, Guan L, Hudson L, Flor-Cisneros A, Nichols A (2009) A singleascending dose of desvenlafaxine administered to healthy, female Japanese subjects. Poster presented at: 1st Meeting of the Asian College of Neuropsychopharmacology, Kyoto, Japan.

26. Nichols Al, Guan L, Abell M, Frick G (2010) Assessing the pharmacokinetics and tolerability of single-ascending doses of desvenlafaxine in healthy Chinese subjects. Poster presented at: Biennial World Congress of the International College of Neuropsychopharmacology, Hong Kong, China.

27. Nichols Al, Abell M, Chen Y, Behrle JA, Frick G, et al. (2013) Effects of desvenlafaxine on the pharmacokinetics of desipramine in healthy adults. Int Clin Psychopharmacol 28: 99-105.

28. Clayton AH, Kornstein SG, Rosas G, Guico-Pabia C, Tourian KA (2009) An integrated analysis of the safety and tolerability of desvenlafaxine compared with placebo in the treatment of major depressive disorder. CNS Spectr 14 183-195. 